\title{
Validity of the Modified Child Psychopathy Scale for Juvenile Justice Center Residents
}

\author{
Bruno Verschuere • Ingrid Candel • Lique Van Reenen • Andries Korebrits
}

Published online: 16 December 2011

(C) The Author(s) 2011. This article is published with open access at Springerlink.com

\begin{abstract}
Adult psychopathy has proven to be an important clinical and forensic construct, but much less is known about juvenile psychopathy. In the present study, we examined the construct validity of the self report modified Child Psychopathy Scale mCPS; Lynam (Psychological Bulletin 120:(2), 209-234, 1997) in a sample of 57 adolescents residing in a Dutch juvenile justice center, aged between 13 and 22 years. The mCPS total score was reliably related to high externalizing problems, low empathy, high anger and aggression, high impulsivity, high (violent) delinquency, and high alcohol/drug use. Unique relations were found for the antisocial-impulsive (mCPS Factor 2), but not the
\end{abstract}

B. Verschuere $(\bowtie)$

Department of Clinical Psychology, University of Amsterdam, Roetersstraat 15 ,

1018, WB Amsterdam, Netherlands

e-mail: b.j.verschuere@uva.nl

B. Verschuere

Department of Psychology, Ghent University,

Ghent, Belgium

B. Verschuere $\cdot$ I. Candel

Faculty of Psychology and Neuroscience, Maastricht University, Maastricht, The Netherlands

I. Candel $\cdot$ L. Van Reenen $\cdot$ A. Korebrits

St. Joseph Foundation,

Cadier en Keer, The Netherlands

A. Korebrits

Department of Forensic Psychiatry, Faculty of Law,

Radboud University Nijmegen,

Nijmegen, The Netherlands

\section{A. Korebrits}

Department of Psychiatry and Neuropsychology,

University Hospital Maastricht,

Maastricht, The Netherlands callous-unemotional facet of psychopathy (mCPS Factor 1). Our findings support the validity of the mCPS in that it encompasses the antisocial-impulsive facet of psychopathy, but it is less clear whether the mCPS sufficiently captures the affective-interpersonal facet of psychopathy.

Keywords Psychopathy Child psychopathy scale . Antisocial $\cdot$ Impulsivity $\cdot$ Aggression

Delinquency is relatively common among adolescents, but only a very small group of adolescent offenders persist in their delinquent behaviour as adults (Moffitt 1993). This small group is responsible for up to half of all crimes committed by adolescents (Farrington et al. 1986; Moffitt 1993; Wolfgang et al. 1972). Early identification of this group would create the opportunity for early intervention. Reviewing several large scale longitudinal studies, Lynam (1996) showed that boys who display antisocial behaviour and ADHD symptoms are most at risk for chronic offending. Frick and colleagues, however, cautioned against an exclusive reliance upon behavioural symptoms, and showed that the prediction of chronic offending can be further improved by including callous/unemotional traits (for a review see Frick and White 2008). This constellation of traits highly resembles a concept from the adult literature: psychopathy.

Psychopathy refers to a clinical construct encompassing both behavioural-lifestyle characteristics (e.g., impulsivity, irresponsibility, sensation seeking and chronic antisocial behaviour) and affective-interpersonal characteristics (e.g., lack of empathy, glibness, arrogance, lying, shallow affect, and lack of guilt; Cleckley 1941; Hare 2003; Patrick 2006). These two facets are encompassed by the most widely used adult psychopathy measure - the Psychopathy Checklist Revised (PCL-R; Hare 2003). PCL-R Factorl captures the 
affective-interpersonal features and PCL-R Factor2 captures the behaviour-lifestyle features. It is debated whether these factors should be further split up in three or even four factors and whether antisocial behaviour should be excluded from the behaviour-lifestyle dimension (Cooke and Michie 2001; Hare 2003). Irrespective of this discussion, there is a consensus that psychopathy encompasses the two broad facets.

Adult psychopathy has proven to be a meaningful and important concept in clinical and forensic settings. Psychopathy is associated with aggression and violence, and psychopathy reliably predicts general, violent, and sexual criminal recidivism (Hare et al. 2000; Quinsey et al. 1995; Salekin et al. 1996). High psychopathic offenders not only relapse more often, but they also relapse sooner and more severely (Barbaree 2005; Harris et al. 1991; Salekin et al. 1996).

The psychopathy construct may help to differentiate "life-course persistent" from "adolescent-limited" antisocial behaviour. Such an endeavour requires the reliable and valid assessment of the psychopathy construct in youth. Several measures of juvenile psychopathy have been developed for this purpose, including the Antisocial Process Screening Device (ASPSD; Frick et al. 2000), the Psychopathy Checklist: Youth Version (PCL:YV; Forth et al. 2003), the Child Psychopathy Scale ([m]CPS; Lynam 1997), and the Youth Psychopathic Traits Inventory (YPI; Andershed et al. 2002).

The self report measures of juvenile psychopathy reliably predict program failure and dropout, institutional antisocial behaviour, and general and violent criminal recidivism (Boccaccini et al. 2007; Falkenbach et al. 2003; Salekin 2008; Spain et al. 2004). Meta-analytic research on 2,867 youth aged between 14 and 19 years showed a reliable association between clinical expert ratings using the PCL: YV and general and violent criminal recidivism (Edens et al. 2007). Accumulating evidence further suggests that juvenile psychopathy, like its adult counterpart, is associated with severe and stable aggression, delinquency, and deficient processing of emotional information (Frick and White 2008). Given the controversy around the juvenile psychopathy construct and the associated risks (e.g., labelling), however, thorough validation of the juvenile psychopathy construct and its measures is essential before implementing it in forensic decision making (Salekin and Lynam 2010; Seagrave and Grisso 2002).

The present study examines the validity of the Child Psychopathy Scale. Using archival data from the Pittsburgh Youth study, Lynam tried to measure psychopathy in a similar way as the adult Psychopathy Checklist (PCL; Hare 2003) by combining items from the Child Behavior Checklist (CBCL; Achenbach 1991) and the Common-Language Q-Sort (CLQ; Caspi et al. 1992) into the Child Psychopathy Scale (CPS; Lynam 1997). Initially, a large set of 300 relevant items was selected. Based on content and psychometric properties (i.e., item-scale correlations and internal consistency), 41 items aimed to tap 13 of the 20 PCL items - were selected. For 7 PCL items, there were no CPS items, for example, because of the difficulties in creating an appropriate youth version of the PCL item (e.g., many short term marital relationships, revocation of conditional release, etc.). With two exceptions (i.e., lack of remorse or guilt, $a=.25$; and parasitic lifestyle, $a=.36$ ), the CPS Scales had sufficient internal consistency $(a=.51-.76)$, and the overall internal consistency of the CPS was very high $(a=.91)$. Data from 508 high-risk community boys from the Pittsburgh Youth study support the reliability and validity of the CPS, showing that CPS scores were associated with high self reported delinquency, high impulsivity, high externalizing problems, and low internalizing problems (Lynam 1997).

The CPS was later revised. Specifically, (1) items were added to increase the reliability and validity of several CPS Scales (e.g., the number of items in the Poverty of Affect Scale rose from 2 to 8), (2) two scales were added: Grandiosity (originally not included because of its lack of correlation with the other CPS Scales) and Boredom Susceptibility (originally not included because of difficulties in the operationalization), and (3) items tapping Criminal Versatility and Juvenile Delinquency were excluded in order to assure that the CPS is a 'pure' personality measure uncontaminated by antisocial behavior (for a theoretical discussion see Cooke and Michie 2001; Lilienfeld and Andrews 1996). As a result, the modified CPS (mCPS) consisted of 55 items (see e.g., Bijttebier and Decoene 2009; Spain et al. 2004). The CPS remains an instrument under development. Because of its lack of correlation with the other CPS Scales, the Grandiosity Scale was deleted again. The present study aimed to investigate the validity of the current, 50-item mCPS (see Table 1).

To examine the construct validity of the mCPS, we measured its association with theoretically relevant criterion variables: age, IQ, impulsivity, internalizing and externalizing mental problems, empathy, aggression, and delinquency. Based on the adult psychopathy literature (Blonigen et al. 2010; Hare 2003; Harpur et al. 1988; Lilienfeld and Widows 2005; Lynam 1997; Patrick 2006; Uzieblo et al. 2007), we expected that juvenile psychopathy as indexed by the mCPS total score would be associated with low age, high impulsivity, high externalizing, high disinhibition, low empathy, high aggression, and high delinquency. Furthermore, different and unique associations were expected for the two facets of psychopathy. The affective-interpersonal facet of psychopathy (i.e., mCPS Factor1) was predicted to be uniquely related to low internalizing problems, and to be more strongly associated with low empathy and high proactive aggression than the antisocial-lifestyle facet of psychopathy (i.e., mCPS Factor2). The latter factor was predicted to show unique relations with high internalizing problems, and to show a stronger relation 
Table 1 Correspondence between Lynam's 50-Item Self Report Child Psychopathy Scale (mCPS) and Hare's Psychopathy Checklist (PCL)

\begin{tabular}{|c|c|c|c|}
\hline PCL Scale & mCPS Scale & $\begin{array}{l}\text { Number of } \\
\text { items in CPS }\end{array}$ & mCPS Item Example \\
\hline \multicolumn{4}{|l|}{ Factor1 } \\
\hline Glibness & Glibness & 4 & Are you talkative? \\
\hline Pathological Lying & Untruthfulness & 5 & Will you usually tell a lie if you think you can get \\
\hline Manipulative & Manipulation & 3 & Do you try to take advantage of other people? \\
\hline Lack of remorse or guilt & Lack of guilt & 3 & Do you usually feel guilty after doing something wrong? \\
\hline Lack of empathy & Callousness & 4 & Are you considerate and thoughtful of other people? \\
\hline Shallow affect & Poverty of affect & 7 & Do you make close friendships with other people? \\
\hline $\begin{array}{l}\text { Failure to accept } \\
\text { responsibility }\end{array}$ & Failure to accept responsability & 3 & $\begin{array}{l}\text { Do you try to blame other people for things that you } \\
\text { have done? }\end{array}$ \\
\hline \multicolumn{4}{|l|}{ Factor2 } \\
\hline Need for stimulation & Boredom susceptibility & 5 & Are you easily bored? \\
\hline Parasistic Lifestyle & Parasistic Lifestyle & 4 & Do you try to see how much you can get away with? \\
\hline Lack of long term goals & Lack of planning & 3 & Do you plan things ahead? \\
\hline Impulsivity & Impulsiveness & 3 & Do you use your head before doing or saying something? \\
\hline Irresponsability & Unreliability & 3 & Are you reliable and dependable? \\
\hline Poor behavioral control & Behavioral Dyscontrol & 3 & Are you easily frustrated? \\
\hline
\end{tabular}

with low age, high impulsivity, high externalizing problems, high disinhibition, high reactive aggression, high alcohol/drug abuse, and high delinquency than mCPS Factor1. The present study extends previous research on the mCPS in important ways. First, we assessed the mCPS on its own (as is likely most often done in clinical and forensic settings), rather than selecting the mCPS items post hoc from the CBCL/CLQ (as was done in several CPS validation studies). This difference in assessment may affect the validity of the mCPS, for example, because the participant may more easily grasp what the mCPS aims to measure when it is assessed as a separate instrument. Such greater face validity may in turn increase the chance that the participant engages in impression management. Therefore, we found it important to examine the validity of the mCPS as a separate instrument. Second, we assessed adolescents residing in a juvenile justice center, whereas previous studies have often examined boys residing in the community. Third, as our study was completed in the Netherlands, our study extends prior work that was largely based on North-American samples.

\section{Method}

\section{Participants}

Participants were adolescents residing in the juvenile justice center "Stichting Jeugdzorg St. Joseph", in South-Limburg of the Netherlands. Data of this study were collected for adolescents who entered the setting between December 19, 2006 and September 19, 2009. Participants completed the assessment procedure as part of the facility program. Written informed consent to use these data for research purposes was obtained from 85 participants (an estimated $75 \%$ of the population). Written parental/caregiver consent was obtained for participants below 16 years of age. mCPS data were available for 62 youth. Because we only had data for four girls, we considered only the data from the boys in our analyses $(n=58)$. Data from one boy were excluded because of excessive missing data (see Results Section). Fifty-seven boys between 13 and 22 years of age $(M=16.75, S D=1.68$ years $)$ took part in this study. Thirtyfour boys $(64 \%)$ were Dutch, with the remaining having a variety of different ethnic backgrounds (European $[n=2]$, Asian $[n=1]$, South-American $[n=5]$, Central-American $[n=$ 1], Mid-Eastern $[n=3]$, North-African $[n=6]$, Black-African $[n=2])$, Not registered $[n=3]$.

\section{Material}

Wechsler Intelligence Scale for Children-III/ Wechsler Adult Intelligence Scale-III (WISC-III/WAIS-III)

IQ was assessed with the Wechsler Intelligence Scale for Children - III (WISC-III; Wechsler 2003) in boys younger than 16 years of age, and with the Wechsler Adult Intelligence Scale (WAIS-III; Wechsler 1997) in those of 16 years or older.

\section{Child Psychopathy Scale (CPS)}

We used self report version of the Child Psychopathy Scale (mCPS; Lynam 1997; see http://www1.psych.purdue.edu/ $\sim$ dlynam/cpspage.htm). This version contains 50 yes-or-no 
questions (e.g., "Are you a good liar?"). These 50 items load on 13 of the 20 PCL items (see Table 1). Moderate to high internal consistency has been reported for different versions of the CPS. Lynam (1997) found $\alpha=.91$ for the 41-item motherreported version in a sample of about 500 boys from the Pittsburgh Youth Study. Falkenbach and colleagues (2003) found $\alpha=.77$ and $\alpha=.90$ for the 55-item self- and parentreport versions, respectively, in a sample of 69 delinquent youth from a juvenile diversion program. Bijttebier and Decoene (2009) found internal consistency of .81, .91, and .68 of the parent-, teacher-, and self-report versions of the 55-item mCPS in a community sample of 182 children. Six-month test-retest reliability of the 58-item mCPS was .87 (Isen et al. 2010).

Using confirmatory factor analyses (CFA) on the original 41-item CPS, Lynam (1997) initially found adequate fit for the "classic" two-factor structure. This two-factor structure also produced better fit than a one factor model for the 55 item version (Bijttebier and Decoene 2009), but fit was low (see also; Isen et al. 2010). To be consistent with Lynam (1997) and Bijttebier and Decoene (2009), and because of extensive research on the 2 -facor model in the adult psychopathy literature, we used the 2-factor model.

\section{The Aggression Questionnaire (AQ)}

The Aggression Questionnaire (AQ; Buss and Perry 1992) consists of 29 items that are rated on a 5-point scale from 1 (completely disagree) to 5 (completely agree), and load on physical aggression (9 items), verbal aggression (5 items), anger ( 7 items), and hostility ( 8 items). A total aggression score can be obtained by summing the scores of the subscales. Meesters and colleagues (1996) reported $\alpha$ 's of .75, $.50, .70, .76$, and .84 for physical aggression, verbal aggression, anger, hostility, and the total score, respectively. Sixweek test-retest reliability ranged from .76 (physical aggression) to .80 (total score).

\section{The Beck Depression Inventory (BDI)}

The Beck Depression Inventory is one of the most widely used instruments to assess depression. The original BDI (Beck et al. 1979) was used. Participants answered how they felt during the last week on 21 items that each had four response options; for example, (1) I do not feel sad; (2) I feel sad; (3) I am sad all the time and I can't snap out of it; (4) I am so sad or unhappy that I can't stand it. Beck and colleagues (Beck et al. 1988 ) reported a mean $a$ of .81 and a test-retest reliably (from 1 to $6 \mathrm{~h}$ to 4 months) ranging between .48 and .86 .

\section{The Barratt Impulsiveness Scale (BIS-11)}

The Barratt Impulsiveness Scale (BIS-11; Patton et al. 1995) is widely used self-report measure of impulsivity. It consists of 30 items that are rated on a 1 (seldom or never) to 4 (nearly always or always) scale. Eight items load on Attentional Impulsivity, 11 items on Motor Impulsivity, and another 11 items on Nonplanning Impulsivity. Patton and colleagues reported $\alpha$ 's ranging from .79 to .83 in four different populations.

\section{The Interpersonal Reactivity Index (IRI)}

The Interpersonal Reactivity Index (IRI; Davis 1983) consists of 28 items scored from 0 (completely does not fit me) to 4 (completely fits me) that tap into four 7-item subscales: Perspective Taking (PT), Empathic Concern (EC), Fantasy (F), and Personal Distress (PD). Following the author's recommendations, no total score is calculated. The IRI measures both cognitive and affective empathy: the tendency to spontaneously adopt the view of other (PT), to experience compassion (EC) or distress in response to observed distressed (PD), and to transpose oneself into fictional situations (F). Davis reported $\alpha$ 's ranging from .70 to .78, and a 60-75 day test-retest reliability ranging from .61 to .82 .

\section{Reactive-Proactive Aggression Questionnaire (RPQ)}

The Reactive-Proactive Aggression Questionnaire (RPQ; Raine et al. 2006) consists of 23 items that are scored 0 (never), 1 (sometimes) or 2 (often). Eleven items measure aggression in response to frustration (Reactive Aggression) and 12 items measure instrumental aggression that serves to achieve one's goals (Proactive Aggression). A total Aggression score is obtained by summing the scores of the two subscales. Raine and colleagues found $\alpha$ 's of .81, .84, and .90, for Reactive Aggression, Proactive Aggression, and the total score, respectively.

\section{Self Reported Delinquency (SRD)}

The Self Reported Delinquency scale (SRD) was a 34-item version of Elliott's SRD measure (Elliott and Ageton 1980) that is answered with yes-or-no responses. The SRD examines the occurrence of a variety of delinquent behaviour, including purposeful damage of goods, gang fights, weapon use, and selling and using drugs. We calculated a sum score for violent delinquency (9 items), selling and using alcohol/ drugs ( 8 items), and a total score (34 items).

\section{Youth Self Report (YSR)}

The original version of the Youth Self Report (YSR; Achenbach 1991) was used. This 112-item self-report instrument assesses emotional and behavioral problems (Social Problems, Thought Problems, Attention Problems, Aggressive Behavior, Delinquent Behavior, Withdrawn, 
Anxious/Depressed, Somatic Complaints). Aggressive Behavior and Delinquent Behavior load on Externalizing, whereas Withdrawn/Depressed, Anxious/Depressed, and Somatic Complaints load on Internalizing. Achenbach reported $\alpha$ 's of .89 for Externalizing, and .91 for Internalizing.

\section{Results}

Missing Data

Missing data were handled following the procedure proposed by Lilienfeld and Widows (2005). First, data from measures with more than $20 \%$ missing data were omitted from analyses. There was a varying number of missing data, but there was data for a minimum of 44 boys for all analyses. Second, missing data from scales with less than $20 \%$ missing data were replaced by the mean of the completed items.

\section{Descriptive Statistics}

Means, standard deviations, and Chronbach's alpha's for all measures can be found in Table 2. The internal consistency of the mCPS factor and total scores are acceptable to good (Barker et al. 1994). mCPS total and factor scores did not differ significantly with ethnicity (Dutch vs. nonDutch), $t$ 's $<1$.

\section{mCPS Total Score}

The correlations between the mCPS total and factor scores and theoretically relevant measures are reported in Table 3. The mCPS total score was negatively associated with age, IRI perspective taking, IRI empathic concern, and positively related to YSR internalizing, externalizing and total problems, BIS-11 motor, non-planning, attentive and total impulsivity, AQ physical and verbal aggression, anger and hostility, RPQ reactive and proactive aggression, and SRD alcohol/drugs, violent and total delinquency. Most correlations were moderate to large.

\section{mCPS Factor Scores}

Inspection of Table 3 shows that, with very few exceptions, bivariate correlations between mCPS factor scores and the criterion-related variables were similar to those between the mCPS total score and the criterion-related variables. The bivariate correlations did not provide evidence for differential associations of the mCPS factors scores with the criterion-related variables. This is perhaps not that surprising given that the two CPS factor scores were very highly correlated, $r=.76, p<.001$. Following the recommendations
Table 2 Mean ( $M$; with Standard deviation, $S D$ ) and internal consistency (Chronbach's $\alpha$ ) of all measures included in the correlation analyses

\begin{tabular}{|c|c|c|}
\hline Measure & $M(S D)$ & $\alpha$ \\
\hline IQ & $88.52(11.64)$ & \\
\hline \multicolumn{3}{|l|}{$\mathrm{mCPS}$} \\
\hline Factor1 & $2.07(1.00)$ & .72 \\
\hline Factor2 & $1.58(1.09)$ & .81 \\
\hline Total & $3.65(1.96)$ & .86 \\
\hline \multicolumn{3}{|l|}{ YSR } \\
\hline Internalizing & $10.47(6.99)$ & .84 \\
\hline Externalizing & $15.90(9.91)$ & .91 \\
\hline Total & $42.35(21.71)$ & .93 \\
\hline BDI & $8.67(6.84)$ & .78 \\
\hline \multicolumn{3}{|l|}{ IRI } \\
\hline Perspective Taking & $12.52(5.26)$ & .71 \\
\hline Empathic Concern & $16.64(5.33)$ & .70 \\
\hline Fantasy & $9.37(5.71)$ & .73 \\
\hline Personal Distress & $8.17(5.42)$ & .72 \\
\hline \multicolumn{3}{|l|}{ BIS-11 } \\
\hline Motor Impulsivity & $21.07(3.69)$ & .51 \\
\hline Non-planning Impulsivity & $24.67(4.88)$ & .71 \\
\hline Attentive Impulsivity & $15.70(3.52)$ & .58 \\
\hline Total & $61.46(9.50)$ & .78 \\
\hline \multicolumn{3}{|l|}{ AQ } \\
\hline Physical Aggression & $27.89(8.75)$ & .86 \\
\hline Verbal Aggression & $15.27(2.70)$ & .40 \\
\hline Anger & $17.70(5.26)$ & .70 \\
\hline Hostility & $19.79(5.94)$ & .77 \\
\hline Total & $80.66(17.97)$ & .89 \\
\hline \multicolumn{3}{|l|}{ RPQ } \\
\hline Reactive Aggression & $10.83(4.49)$ & .85 \\
\hline Proactive Aggression & $5.90(4.94)$ & .88 \\
\hline Total & $16.73(8.83)$ & .92 \\
\hline \multicolumn{3}{|l|}{ SRD } \\
\hline Alcohol/Drugs & $3.61(2.12)$ & .77 \\
\hline Violent & $3.86(2.49)$ & .77 \\
\hline Total & $14.02(7.87)$ & .92 \\
\hline
\end{tabular}

$m C P S$ Child Psychopathy Scale; YSR Youth Self Report; BDI Beck Depression Inventory; IRI Interpersonal Reactivity Index; BIS-11 Barratt Impulsiveness Scale 11; $A Q$ Aggression Questionnaire; $R P Q$ Reactive-Proactive Aggression Questionnaire; SRD Self Reported Delinquency

by Meng and colleagues (1992), we used Steiger's Z-test to statistically compare the bivariate correlations for the two mCPS factors. mCPS Factor2 correlated more strongly with AQ Anger, $Z=2.45, p<.05$, BIS-11 Attentive Impulsivity, $Z=2.04, p<.05$, and Bis-11 total, $Z=2.91, p<.01$, than mCPS Factor1. 
Table 3 Correlations between the mCPS total and factor scores and the criterion measures; partial correlations are given between parentheses
${ }^{*} p<.05 ; * * p<.01 ; m C P S$ Child Psychopathy Scale; YSR Youth Self Report; BDI Beck Depression Inventory; IRI Interpersonal Reactivity Index; $B I S-11$ Barratt Impulsiveness Scale 11; $A Q$ Aggression Questionnaire; $R P Q$ Reactive-Proactive Aggression Questionnaire; SRD Self Reported Delinquency. Bivariate correlations that differ significantly from each other are marked in bold

\begin{tabular}{|c|c|c|c|c|}
\hline Measure & $n$ & $\begin{array}{l}\text { mCPS } \\
\text { Factor1 }\end{array}$ & $\begin{array}{l}\text { mCPS } \\
\text { Factor2 }\end{array}$ & $\begin{array}{l}\text { mCPS } \\
\text { Total Score }\end{array}$ \\
\hline Age & 55 & $-.27 *(.03)$ & $-.39 * *(-.29 *)$ & $-.35 * *$ \\
\hline \multicolumn{5}{|l|}{ IQ } \\
\hline Verbal & 47 & $.10(.02)$ & $.12(.06)$ & .12 \\
\hline Performance & 47 & $-.00(.06)$ & $-.06(-.09)$ & -.03 \\
\hline Total & 46 & $.06(.04)$ & $.04(.00)$ & .05 \\
\hline \multicolumn{5}{|l|}{ YSR } \\
\hline Internalizing & 50 & $.27(.01)$ & $.34 *(.22)$ & $.33^{*}$ \\
\hline Externalizing & 50 & $.66^{* *}(.08)$ & $.77 * *(.55 * *)$ & $.77 * *$ \\
\hline Total & 50 & $.55 * *(.05)$ & $.69 * *(.51 * *)$ & $.67 * *$ \\
\hline BDI & 44 & $.20(.00)$ & $.26(.17)$ & .24 \\
\hline \multicolumn{5}{|l|}{ IRI } \\
\hline Perspective Taking & 52 & $-.39 * *(-.08)$ & $-.46 * *(-.27)$ & $-.46^{* *}$ \\
\hline Empathic Concern & 52 & $-.27(-.08)$ & $-.29 *(-.13)$ & $-.30 *$ \\
\hline Fantasy & 51 & $-.03(.11)$ & $-.13(-.17)$ & -.09 \\
\hline Personal Distress & 51 & $.16(.01)$ & $.20(.13)$ & .19 \\
\hline \multicolumn{5}{|l|}{ BIS-11 } \\
\hline Motor Impulsivity & 55 & $.52 * *(-.06)$ & $.64 * *(.45 * *)$ & $.62 * *$ \\
\hline Non-planning Impulsivity & 56 & $.47 * *(-.00)$ & $.62 * *(.46 * *)$ & $.59 * *$ \\
\hline Attentive Impulsivity & 56 & $.37 * *(-.07)$ & $.54 * *(.42 * *)$ & $.49 * *$ \\
\hline Total & 56 & $.58^{* *}(-.01)$ & $.77 * *(.62 * *)$ & $.73 * *$ \\
\hline \multicolumn{5}{|l|}{$\mathrm{AQ}$} \\
\hline Physical Aggression & 48 & $.59 * *(.31)$ & $.56 * *(.21)$ & $.61 * *$ \\
\hline Verbal Aggression & 48 & $.55 * *(.14)$ & $.63 * *(.39 * *)$ & $.63^{* *}$ \\
\hline Anger & 48 & $.52 * *(-.05)$ & $.71 * *(.57 * *)$ & $.69 * *$ \\
\hline Hostility & 48 & $.40 * *(.10)$ & $.45 * *(.25)$ & $.46^{* *}$ \\
\hline Total & 48 & $.65 * *(.23)$ & $.72 * *(.46 * *)$ & $.74 * *$ \\
\hline \multicolumn{5}{|l|}{ RPQ } \\
\hline Reactive Aggression & 53 & $.56 * *(.08)$ & $.68 * *(.48 * *)$ & $.67 * *$ \\
\hline Proactive Aggression & 53 & $.54 * *(.15)$ & $.61 * *(.36 * *)$ & $.61 * *$ \\
\hline Total & 53 & $.58 * *(.13)$ & $.69 * *(.46 * *)$ & $.68 * *$ \\
\hline \multicolumn{5}{|l|}{ SRD } \\
\hline Alcohol/Drugs & 52 & $.26(.08)$ & $.27(.12)$ & $.28^{*}$ \\
\hline Violent & 51 & $.50 * *(.15)$ & $.55^{* *}(.30 *)$ & $.56^{* *}$ \\
\hline Total & 51 & $.49 * *(.22)$ & $.49 * *(.20)$ & $.52 * *$ \\
\hline
\end{tabular}

Because suppressor effects have been reported between psychopathy factor scores in the prediction of criterionrelated variables (Blonigen et al. 2010), we also calculated partial correlations. Partial correlations shed light on the unique relationship between the factor scores and the criterion-related variables. After controlling for mCPS Factor2, none out of $18(0 \%)$ significant bivariate correlations for mCPS Factor 1 remained significant. After controlling for mCPS Factor1, 14 out of 20 (70\%) significant bivariate correlations for mCPS Factor 2 remained significant. This suggests that mCPS Factor 2 rather than Factor 1 uniquely relates to the criterion-related variables. Analyses with the rationally derived, but untested, 3-factor structure
(Dividing Factor1 into an Affect and an Interpersonal factor, and excluding Behavioral Dyscontrol from Factor2; Spain et al. 2004) showed a similar, yet less dramatic, pattern. After controlling for the other two factors, the number of significant correlations dropped from 17 to 5 for mCPS Affect (correlations with YSR externalizing, BIS-11 Non-planning Impulsivity, AQ Physical Aggression, AQ total, and RPQ total remained significant), and from 17 to 2 for mCPS Interpersonal (correlations with YSR internalizing and YSR total remained significant; in addition IRI Fantasy became significant). For mCPS Lifestyle, however, 11 out of 20 correlations remained significant after controlling for the other two factors (correlations with YSR externalizing, 
YSR total, BIS-11 Motor Impulsivity, BIS-11 Non-planning Impulsivity, BIS-11 Attentive Impulsivity, BIS-11 total, AQ anger, AQ total, RPQ reactive aggression, RPQ proactive aggression, and RPQ total remained significant).

\section{Discussion}

Researchers have expressed great concern with regard to the concept of juvenile psychopathy (Hart et al. 2002). Several characteristics of psychopathy may be too common among adolescents and reflect transient developmental states rather than stable personality traits. Moreover, labeling of youth as psychopathic, accurate or not, can have great consequences. On the other hand, accurate identification of juvenile psychopathy could have great benefits, both for the individual and for society. Thus, thorough validation of juvenile psychopathy measures is required before applying them in juvenile forensic settings (Hart et al. 2002; Seagrave and Grisso 2002). Seagrave and Grisso argued that it needs to be firmly established that juvenile psychopathy (1) can be measured reliably, (2) is similar to its adult counterpart, and (3) is stable across time. The present study tackles the first two aspects, by assessing the modified Child Psychopathy Scale along with a range of criterion-related variables in a sample of 57 juvenile justice center residents.

We found that the internal consistency of the mCPS was moderate for mCPS Factor1 $(\alpha=.72)$, and good for mCPS Factor2 $(\alpha=.81)$ and mCPS Total score $(\alpha=.86)$. In a community sample of 182 Flemish adolescents, Bijttebier and Decoene (2009), however, found that the internal consistency of the self-report mCPS (Factor1: $\alpha=.54$, Factor2: $\alpha=.50$, Total: $\alpha=.68$ ) was not sufficient (i.e., lower than .70 ), and lower than that scored by the parent (Factor1: $\alpha=.70$, Factor2: $\alpha=.70$, Total: $\alpha=.81$ ) or the teacher (Factor1: $\alpha=.81$, Factor2: $\alpha=.85$, Total: $\alpha=.91$ ). Age differences may account for these findings. Whereas our sample had a mean age of 16.75 years, the Flemish community sample had a mean age of 13.20 years and younger children may have had difficulty understanding the questions. Indeed, the same group (Roose et al. 2010) found somewhat better internal consistency in 455 Flemish adolescents with a mean age of 16.67 years (Factor1: $\alpha=.67$, Factor2: $\alpha=.64$, Total: $\alpha=.77)$. Furthermore, the internal consistency of the current 50 -item version of the mCPS may be better than the 55 -item version used in the Flemish community samples. Finally, our sample (juvenile boys) may better resemble the sample in which the mCPS was developed: boys at high risk for delinquency. Douglas and colleagues (Boccaccini et al. 2007; Douglas et al. 2008; Spain et al. 2004) found moderate to good internal consistency for mCPS total score $(\alpha=.78$ to .87$)$ in different samples of adolescent offenders with a mean age around 15-16 years. Taken together, the data indicate that the internal consistency of the self report mCPS is adequate in male adolescent forensic samples, but not necessarily in other samples (e.g., girls, younger children, the community).

As predicted, the mCPS total score was associated with low age, low empathy (IRI), high externalizing (YSR), high impulsivity (BIS-11), high aggression (AQ, RPQ), and high delinquency (SRD). The associations were moderate to large, with most correlations in the .30 to .70 range. Of particular interest for forensic decision making is the association between juvenile psychopathy on the one hand and aggression and (violent) delinquency on the other hand. As such, juvenile psychopathy, as assessed with the mCPS, indeed seems to look like its adult counterpart (Hare 2003; Harpur et al. 1988; Lilienfeld and Andrews 1996; Uzieblo et al. 2007). Two findings qualify this finding.

First, the mCPS was positively related to YSR internalizing problems. This is unexpected, as it would indicate that the higher the psychopathy score, the more neurotic, anxious, worried, and stressed the adolescent is (see also Lee et al. 2010). This unexpected association is not an isolated finding. Lynam (1997) observed a positive correlation between the mCPS and internalizing problems. Similarly, Salekin and colleagues (2005) observed a positive association between neuroticism and juvenile psychopathy as assessed by both the mCPS and the APSD. Salekin and colleagues reasoned that the behavioral consequences of juvenile psychopathy (e.g., incarceration) may cause anxiety, and they regarded anxiety as a positive sign that may provide a useful starting point for treatment. Although we would like to embrace this intriguing and optimistic possibility, it needs to be admitted that it is post hoc and not testable due to the correlational nature of the data.

Second, whereas the data for the mCPS total score support the validity of the juvenile psychopathy concept, the results for the mCPS factor scores are not so much in line with the adult psychopathy literature. We did not find the predicted differential and unique pattern of relations for the two mCPS factors. Based upon the adult literature, we expected that mCPS Factor 1 would be inversely related to internalizing and negligibly related to externalizing. We also expected that mCPS Factor2 would be positively related to both externalizing and neuroticism. Predictions were confirmed for mCPS Factor2, but not for mCPS Factor1. It has previously been argued that suppressor effects might obscure these effects (Benning et al. 2005; Blonigen et al. 2010). However, accounting for suppressor effects using partial correlations did not reveal the expected effects for mCPS Factor1. Taken together, the mCPS encompasses the antisocial-impulsive facet of psychopathy, but it is less clear whether it sufficiently captures the affective-interpersonal facet of psychopathy. A more extensive and a more indirect (i.e., Benning et al. 2005; Birbaumer et al. 2005; Frick and 
White 2008; Patrick 1994) assessment of affective-interpersonal psychopathy features may clarify this issue.

This study is not without its limitations. First, with a minimum of 44 participants in the analyses, sample size was modest. Second, and most notably, the present findings are based upon self-report measures. Although these measures were well-validated and may provide unique information (Lilienfeld and Andrews 1996), a downside is that psychopathy is associated with lack of insight (Hare 2003) and is subject to presentation biases and strategies. To that extent it is unfortunate that we had no other-report or outcome measures (e.g., rule-breaking during treatment or recidivism). Despite these limitations, our study indicates that (1) the internal consistency of the self report mCPS is adequate in male adolescent forensic samples, and that (2) the mCPS total score was reliably related to the high externalizing problems, low empathy, high anger and aggression, high impulsivity, high (violent) delinquency, and high alcohol/drug use, yet (3) question whether the mCPS sufficiently captures the affective-interpersonal facet of psychopathy.

Acknowledgement This work was supported by the Research Foundation Flanders - FWO. The authors wish to thank Donald Lynam for consultation regarding the mCPS and James Schmidt for language editing.

Open Access This article is distributed under the terms of the Creative Commons Attribution Noncommercial License which permits any noncommercial use, distribution, and reproduction in any medium, provided the original author(s) and source are credited.

\section{References}

Achenbach, T. M. (1991). Manual for the child behavior checklist and 1991 profile. Burlington: University of Vermont.

Andershed, H., Kerr, M., Stattin, H., \& Levander, S. (2002). Psychopathic traits in non-referred youths: Initial test of a new assessment tool. In E. Blaauw \& L. Sheridan (Eds.), Psychopaths: current international perspectives (pp. 131-158). The Hague: Elsevier.

Barbaree, H. E. (2005). Psychopathy, treatment behavior, and recidivism - an extended follow-up of Seto and Barbaree. Journal of Interpersonal Violence, 20(9), 1115-1131.

Barker, C., Pistrang, N., \& Elliott, R. (1994). Research methods in clinical and counseling psychology. Chichester: Wiley.

Beck, A. T., Rush, A. J., Shaw, B. F., \& Emery, G. (1979). Cognitive therapy of depression. New York: Guilford Press.

Beck, A. T., Steer, R. A., \& Garbin, M. G. (1988). Psychometric properties of the beck depression inventory - 25 years of evaluation. Clinical Psychology Review, 8, 77-100.

Benning, S. D., Patrick, C. J., \& Iacono, W. G. (2005). Psychopathy, startle blink modulation, and electrodermal reactivity in twin men. Psychophysiology, 42, 753-762.

Bijttebier, P., \& Decoene, S. (2009). Assessment of psychopathic traits in children and adolescents further validation of the antisocial process screening device and the childhood psychopathy scale. European Journal of Psychological Assessment, 25(3), 157-163.
Birbaumer, N., Viet, R., Lotze, M., Erb, M., Hermann, C., Grodd, W., et al. (2005). Deficient fear conditioning in psychopathy - a functional magnetic resonance imaging study. Archives of General Psychiatry, 62(7), 799-805.

Blonigen, D. M., Patrick, C. J., Douglas, K. S., Poythress, N. G., Skeem, J. L., Lilienfeld, S. O., et al. (2010). Multimethod assessment of psychopathy in relation to factors of internalizing and externalizing from the personality assessment inventory: the impact of method variance and suppressor effects. Psychological Assessment, 22(1), 96-107.

Boccaccini, M. T., Epstein, M., Poythress, N., Douglas, K. S., Campbell, J., Gardner, G., et al. (2007). Self-report measures of child and adolescent psychopathy as predictors of offending in four samples of justice-involved youth. Assessment, 14(4), 361374.

Buss, A. H., \& Perry, M. (1992). The aggression questionnaire. Journal of Personality and Social Psychology, 63(3), 452459.

Caspi, A., Block, J., Block, J. H., Klopp, B., Lynam, D., Moffitt, T. E., et al. (1992). A "common-language" version of the California child Q-set for personality assessment. Psychological Assessment, $44,512-523$.

Cleckley, H. (1941). The mask of sanity. St. Louis: Mosby.

Cooke, D. J., \& Michie, C. (2001). Refining the construct of psychopathy: towards a hierarchical model. Psychological Assessment, 13, 171-188.

Davis, M. H. (1983). Measuring individual-differences in empathy evidence for a multidimensional approach. Journal of Personality and Social Psychology, 44(1), 113-126.

Douglas, K. S., Epstein, M. E., \& Poythress, N. G. (2008). Criminal recidivism among juvenile offenders: testing the incremental and predictive validity of three measures of psychopathic features. Law and Human Behavior, 32(5), 423-438.

Edens, J. F., Campbell, J. S., \& Weir, J. M. (2007). Youth psychopathy and criminal recidivism: a meta-analysis of the psychopathy checklist measures. Law and Human Behavior, 31(1), 53-75.

Elliott, D. S., \& Ageton, S. S. (1980). Reconciling race and classdifferences in self-reported and official estimates of delinquency. American Sociological Review, 45(1), 95-110.

Falkenbach, D. M., Poythress, N. G., \& Heide, K. M. (2003). Psychopathic features in a juvenile diversion population: reliability and predictive validity of two self-report measures. Behavioral Sciences \& the Law, 21(6), 787-805.

Farrington, D. P., Ohlin, L. E., \& Wilson, J. Q. (1986). Understanding and controlling crime: toward a new research strategy. New York: Springer.

Forth, A., Kosson, D. S., \& Hare, R. D. (2003). Psychopathy checklist: youth version: manual. Toronto: MHS.

Frick, P. J., Bodin, S. D., \& Barry, C. T. (2000). Psychopathic traits and conduct problems in community and clinic-referred samples of children: further development of the psychopathy screening device. Psychological Assessment, 12(4), 382-393.

Frick, P. J., \& White, S. F. (2008). Research review: the importance of callous-unemotional traits for developmental models of aggressive and antisocial behavior. Journal of Child Psychology and Psychiatry, 49(4), 359-375.

Hare, R. D. (2003). The hare psychopathy checklist - revised. Toronto: Multi-Health Systems.

Hare, R. D., Clark, D., Grann, M., \& Thornton, D. (2000). Psychopathy and the predictive validity of the PCL-R: an international perspective. Behavioral Sciences \& the Law, 18(5), 623-645.

Harpur, T. J., Hakstian, A. R., \& Hare, R. D. (1988). Factor structure of the psychopathy checklist. Journal of Consulting and Clinical Psychology, 56, 741-747.

Harris, G. T., Rice, M. E., \& Cormier, C. A. (1991). Psychopathy and violent recidivism. Law and Human Behavior, 15(6), 625-637. 
Hart, S. D., Watt, K. A., \& Vincent, G. M. (2002). Commentary on Seagrave and Grisso: impressions of the state of the art. Law and Human Behavior, 26(2), 241-245.

Isen, J., Raine, A., Baker, L., Dawson, M., Bezdjian, S., \& Lozano, D. I. (2010). Sex-specific association between psychopathic traits and electrodermal reactivity in children. Journal of Abnormal Psychology, 119(1), 216-225.

Lee, Z., Salekin, R. T., \& Iselin, A. R. (2010). Psychopathic traits in youth: is there evidence for primary and secondary subtypes? Journal of Abnormal Child Psychology, 38, 381-393.

Lilienfeld, S. O., \& Andrews, B. P. (1996). Development and preliminary validation of a self-report measure of psychopathic personality traits in noncriminal populations. Journal of Personality Assessment, 66, 488-524.

Lilienfeld, S. O., \& Widows, M. R. (2005). Psychopathic personality inventory-revised: professional manual. Lutz: Psychological Assessment Resources, Inc.

Lynam, D. R. (1996). Early identification of chronic offenders: who is the fledgling psychopath? Psychological Bulletin, 120(2), 209-234.

Lynam, D. R. (1997). Pursuing the psychopath: capturing the fledgling psychopath in a nomological net. Journal of Abnormal Psychology, 106(3), 425-438.

Meesters, C., Muris, P., Bosma, H., Schouten, E., \& Beuving, S. (1996). Psychometric evaluation of the Dutch version of the aggression questionnaire. Behaviour Research and Therapy, 34 (10), 839-843.

Meng, X. L., Rosenthal, R., \& Rubin, D. B. (1992). Comparing correlated correlation-coefficients. Psychological Bulletin, 111 (1), 172-175.

Moffitt, T. E. (1993). Adolescence-limited and life-course-persistent antisocial-behavior - a developmental taxonomy. Psychological Review, 100(4), 674-701.

Patrick, C. J. (1994). Emotion and psychopathy: startling new insights. Psychophysiology, 31, 319-330.

Patrick, C. J. (Ed.). (2006). Handbook of psychopathy. New York: Guilford Press.

Patton, J. H., Stanford, M. S., \& Barratt, E. S. (1995). Factor structure of the Barratt impulsiveness scale. Journal of Clinical Psychology, 51(6), 768-774.

Quinsey, V. L., Rice, M. E., \& Harris, G. T. (1995). Actuarial prediction of sexual recidivism. Journal of Interpersonal Violence, 10 (1), 85-105.
Raine, A., Dodge, K., Loeber, R., Gatzke-Kopp, L., Lynam, D., Reynolds, C., et al. (2006). The reactive-proactive aggression questionnaire: differential correlates of reactive and proactive aggression in adolescent boys. Aggressive Behavior, 32(2), 159 171.

Roose, A., Bijttebier, P., Decoene, S., Claes, L., \& Frick, P. J. (2010). Assessing the affective features of psychopathy in adolescence: a further validation of the inventory of callous and unemotional traits. Assessment, 17(1), 44-57.

Salekin, R. T. (2008). Psychopathy and recidivism from midadolescence to young adulthood: cumulating legal problems and limiting life opportunities. Journal of Abnormal Psychology, 117 (2), 386-395.

Salekin, R. T., Leistico, A. M. R., Trobst, K. K., Schrum, C. L., \& Lochman, J. E. (2005). Adolescent psychopathy and personality theory - the interpersonal circumplex: expanding evidence of a nomological net. Journal of Abnormal Child Psychology, 33(4), 445-460.

Salekin, R. T., \& Lynam, R. T. (2010). Handbook of child and adolescent psychopathy. New York: Guilford Press.

Salekin, R. T., Rogers, R., \& Sewell, K. W. (1996). A review and metaanalysis of the psychopathy checklist and psychopathy checklistrevised: predictive validity of dangerousness. Clinical Psychology: Science and Practice, 3(3), 203-215.

Seagrave, D., \& Grisso, T. (2002). Adolescent development and the measurement of juvenile psychopathy. Law and Human Behavior, 26(2), 219-239.

Spain, S. E., Douglas, K. S., Poythress, N. G., \& Epstein, M. (2004). The relationship between psychopathic features, violence and treatment outcome: the comparison of three youth measures of psychopathic features. Behavioral Sciences \& the Law, 22(1), 85102.

Uzieblo, K., Verschuere, B., \& Crombez, G. (2007). The psychopathic personality inventory: construct validity of the two-factor structure. Personality and Individual Differences, 43(4), 657-667.

Wechsler, D. (1997). WAIS-III, WMS-III: technical and interactive manual. San Antonio: The Psychological Corporation.

Wechsler, D. (2003). Wechsler intelligence scale for children - fourth edition: technical and interactive manual. San Antonio: The Psychological Corporation.

Wolfgang, M. E., Figlio, R. M., \& Sellin, T. (1972). Delinquency in a birth cohort. Chicago: University of Chicago Press. 